\title{
Nonmotor Functions of the Cerebellum: An Introduction
}

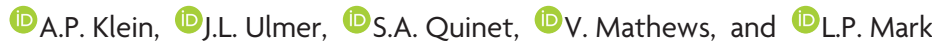

$\mathrm{T}$ he concept of nonmotor functions of the cerebellum (little cerebrum $)^{1}$ is an intriguing proposal that has garnered little attention in the past but has become a relatively recent focal point for neuroscience investigators. The preponderance of anatomic and clinical evidence supporting the traditional view of the cerebellum as a motor mechanism has understandably overwhelmed the sporadic reports of behavioral and intellectual dysfunction associated with cerebellar pathology during the 19th and most of the 20th century. ${ }^{2-7}$ Developments during the past 25 years, coinciding with the development of functional MR imaging, however, have greatly increased our awareness and understanding of cerebellar cognitive functions. Neuroimaging in conjunction with anatomic and clinical investigations is helping to cultivate new ways of thinking about cerebellar organization and function. This vignette will introduce some of these major observations of nonmotor cerebellar functions from a neuroradiologic perspective.

The correlation of cerebellar function and morphology has been a long-standing mystery that raises interesting questions. Although the cerebellum accounts for only about $10 \%$ of the mass of the brain, why does it contain as many neurons as all the rest of the central nervous system combined ${ }^{1}$ Does this imply the existence of underappreciated functions beyond modulation of motor activities? Why did the lateral aspect of the human cerebellum, the cerebellar hemispheres, undergo enormous enlargement during the course of human evolution? ${ }^{8}$ Furthermore, why did this lateral cerebellar growth seem to parallel the evolutionary enlargement of the prefrontal cortex? ${ }^{9,10}$ Functional MR imaging combined with clinical observations provide a novel backdrop to frame the answers.

More recent concepts of cerebellar organization provide a more complete picture of the cerebellum. The traditional morphologic description of the cerebellum subdivides it into lobes, lobules, and zones (Fig 1). The phylogenetic description cate-

From the Medical College of Wisconsin, Department of Radiology, Neuroradiology Section, Froedtert Hospital, Milwaukee, Wisconsin.

Please address correspondence to Leighton P. Mark, MD, Department of Radiology, Neuroradiology Section, Froedtert Hospital, 9200 West Wisconsin Ave, Milwaukee, WI 53226; e-mail: Imark@mcw.edu

http://dx.doi.org/10.3174/ajnr.A4720 gorizes the cerebellum into the vestibulocerebellum (archicerebellum), spinocerebellum (paleocerebellum), and cerebrocerebellum (neocerebellum) (Fig 2). ${ }^{11}$ The oldest portion, the vestibulocerebellum, primarily receives input fibers from the vestibular system. The phylogenetically intermediate component, the spinocerebellum, receives fiber input directly from the spinal cord. The newest part, the cerebrocerebellum, receives input from many different areas of the cerebral cortex. Interesting observations from fMRI studies, however, offer a different type of cerebellar organization based on function. Mapping of cognitive functions shows a lateral cerebellar distribution, while the sensorimotor cerebellar functions are more medially located (Fig 3). ${ }^{12}$ This medial-to-lateral functional gradient also applies to the group of 3 deep cerebellar nuclei (fastigial; interposed, consisting of the globose and emboliform nuclei; and dentate). The cognitive functions of the cerebellum, therefore, are primarily distributed in the lateral aspect of the neocerebellum and ventral lateral aspect of the dentate nuclei. ${ }^{13}$ These same areas have shown an enormous increase in size during hominid evolutionary development, correlating with similar unusually large increases in prefrontal and association cortices during the same phylogenetic period. ${ }^{14,15}$ The mapping of associative learning with emotional, motor, and cognitive functions also reveals a medial-to-lateral cerebellar distribution (Fig 4). ${ }^{16}$

Asymmetry of cerebellar functions is another interesting feature exposed by lesion and fMRI investigations. Language, for instance, lateralizes to the right posterior cerebellar hemisphere (in individuals who are left cerebral hemisphere language dominant), and visuospatial function lateralizes to the left posterior hemisphere. ${ }^{17,18}$ Executive functions, however, seem to be bilateral, while affective functions are primarily midline in the socalled "limbic cerebellum" (Fig 5). In addition, recent restingstate functional connectivity studies that explored functional coupling showed asymmetrically organized cerebral cortical networks in which functional coupling is stronger on one side of the brain than the other. A fascinating corollary observation is the parallel-though-reversed asymmetry of that functional coupling in the cerebellum. ${ }^{19}$ In other words, the cerebellum not only reflects a homotopic map of the cerebral cortex but also the asymmetric functional organization of the cerebrum. These discoveries, therefore, not only demonstrate the novel 


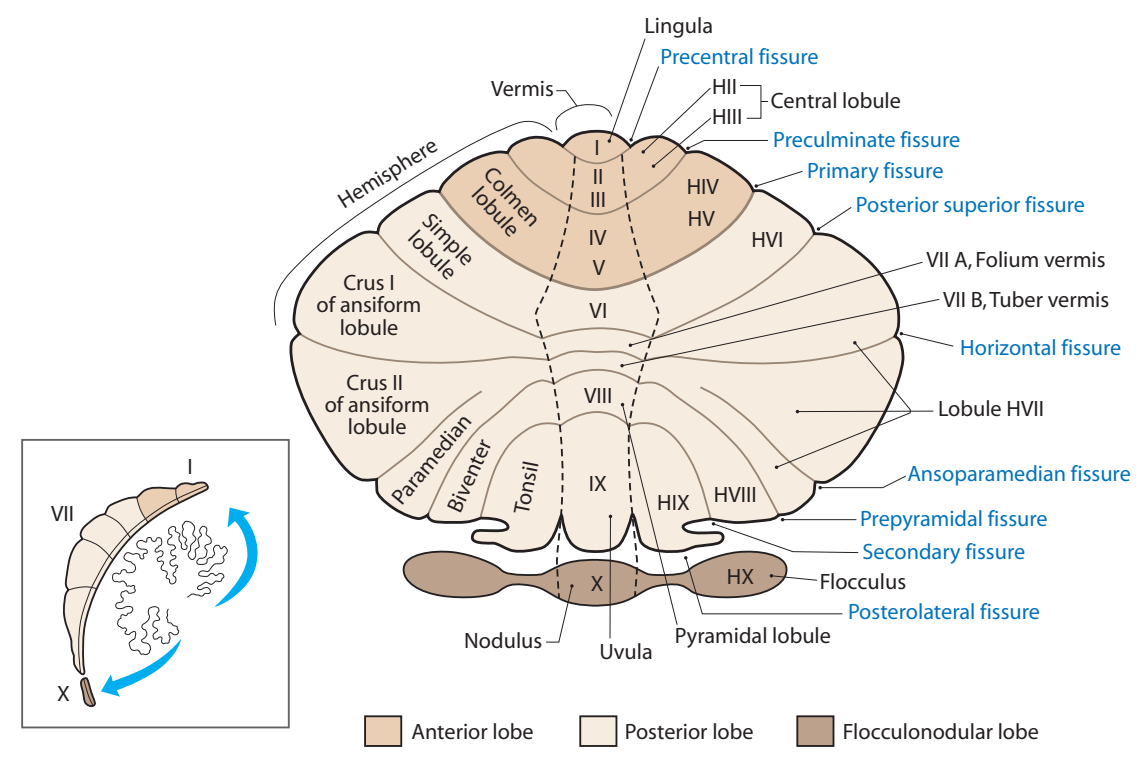

FIG 1. Unfolded view of the cerebellar cortex showing the lobes, lobules (by name on the right and number on the left), and main fissures (blue font). The hemispheric lobules are designated with the prefix $\mathrm{H}$ followed by the Roman numeral indicating their corresponding vermian lobules. Adapted from Haines DE. Fundamental Neuroscience for Basic and Clinical Applications. 4th ed. Philadelphia: Elsevier/Saunders; 2013 with permission of Elsevier. ${ }^{30}$

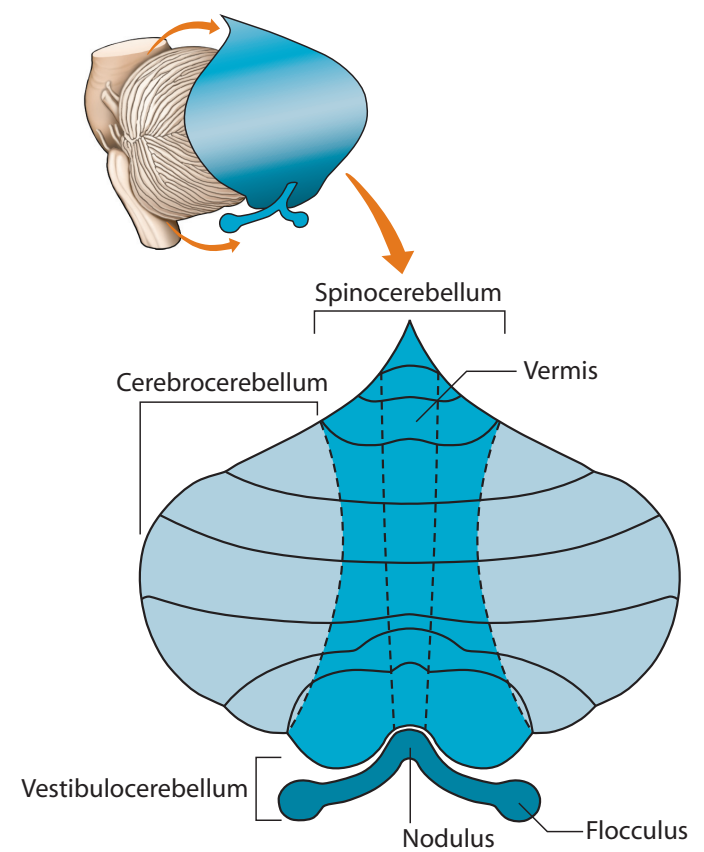

FIG 2. The cerebrocerebellum is the phylogenetically newest and largest portion of the cerebellum. It primarily receives input indirectly from many cerebral cortical areas. The spinocerebellum occupies the median and paramedian zone of the cerebellum and receives input directly from the spinal cord. The vestibulocerebellum is the phylogenetically oldest part of the cerebellum, and it receives input from the vestibular nuclei of the brain stem. Adapted with permission from Purves et al."

concept of nonmotor cerebellar functions but also a particular set pattern of organization of those functions within the cerebellum.

A closer examination of the functional maps of the cerebellum reveals even greater levels of detailed organization. ${ }^{20}$ The motor tasks of the foot, hand, and face, for instance, demonstrate a somatotopic distribution predominantly at the medial aspect of the

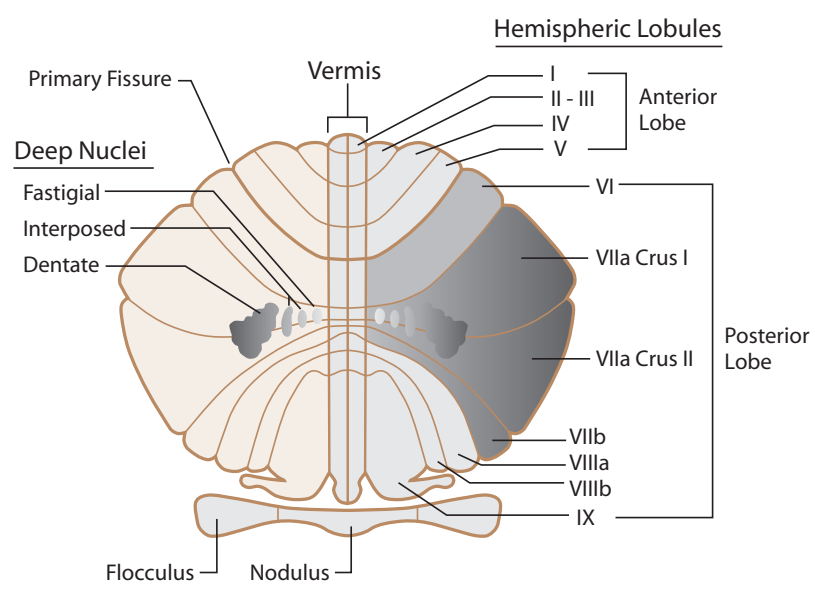

Sensorimotor

Cognitive

FIG 3. Unfolded view of the cerebellum illustrating sensorimotor-tocognitive functions distributed in a gradient-like fashion from medial to lateral. The sensorimotor functions are distributed more toward the midline, while the cognitive functions are located more laterally in the cerebellar hemispheres. The same medial-to-lateral organization is seen in the corresponding cerebellar nuclei. Adapted with permission from Fatemi et al. ${ }^{12}$

anterior lobe of the cerebellum, but surprisingly, this same somatotopic relationship is also reflected in a mirror image fashion in the posterior lobe (Fig 6). When cerebellar maps of the cerebral association cortices are included on a sagittal view of the left cerebellar hemisphere, several broad organizing principles become evident (Fig 7). Most of the cerebellum between the anterior and posterior lobe motor areas maps to cerebral association areas. ${ }^{20-23}$ The amount of cerebellum dedicated to a particular cerebral network is proportional to the size of that cerebral network. In other words, large cerebral networks are coupled to correspondingly large cerebellar territories. The only exceptions are the primary visual and auditory cortices, which are not represented in the 


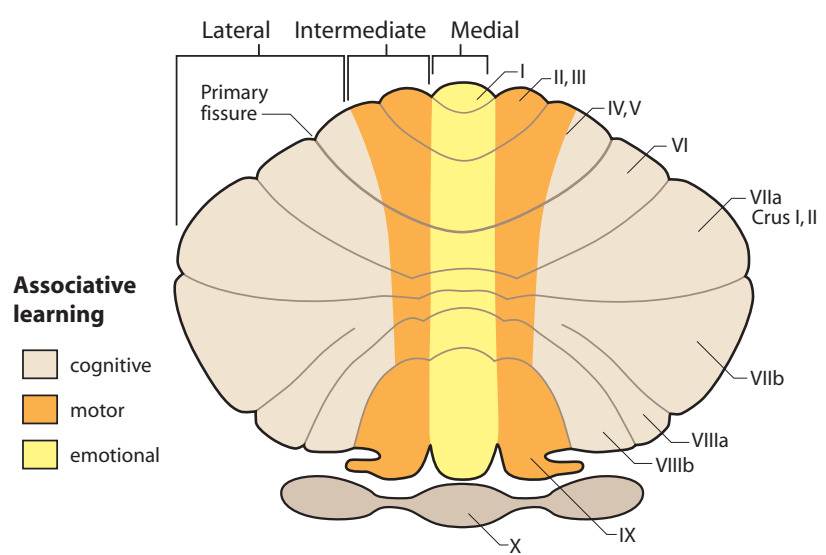

FIG 4. Unfolded view of the cerebellum demonstrating associative learning with emotional tasks located in the medial zone (yellow). Motor tasks locate to the intermediate zone (orange), and cognitive tasks occupy most of the cerebellar hemisphere in the lateral zone (beige). Adapted from Timmann D, Drepper J, Frings M, et al. The human cerebellum contributes to motor, emotional and cognitive associative learning: a review. Cortex 2010;46:845-57 with permission of Elsevier. ${ }^{16}$

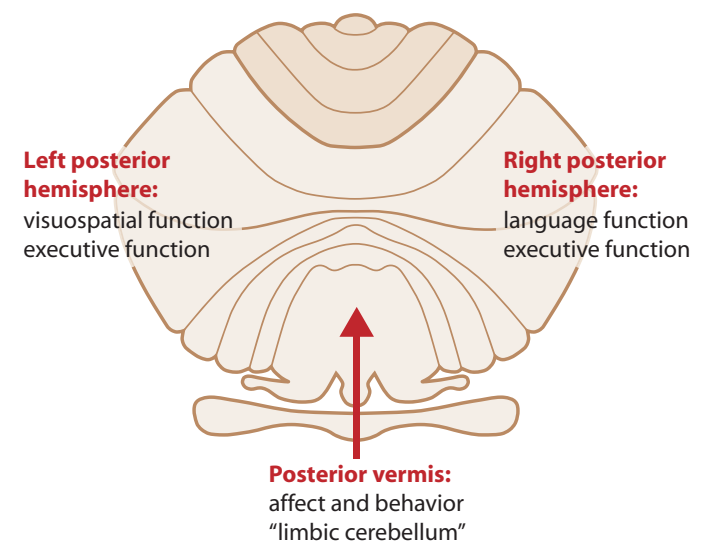

FIG 5. Unfolded view of the cerebellum showing the asymmetric distribution of some cerebellar functions. The right cerebellar hemisphere is associated with language, and the left cerebellar hemisphere, with visuospatial functions. Executive functions, including verbal working memory, are related to both hemispheres. Attention is also a neocerebellar function. The vermis or "limbic cerebellum" is involved in modulating affective behavior. Adapted from Konczak J, Timmann D. The effect of damage to the cerebellum on sensorimotor and cognitive function in children and adolescents. Neurosci Biobehav Rev 2007;31:1101-13 with permission of Elsevier. ${ }^{17}$

human cerebellum. Figure 7 shows the primary cerebellar map with motor functions in the anterior lobe followed by representations of premotor networks, executive control networks, and then limbic-association networks, sometimes also referred to as the default network. The secondary map continues around the cerebellum in reverse order with a flipped representation of the primary map. Crura I and II form the junction between the primary and secondary maps. A map of the entire cerebellum also provides an important overview (Fig 8). Most of the human cerebellum maps to association areas rather than the motor cortex. Those association areas also include executive control networks and the default network. This pattern of distribution of cerebellar functions implies that most of the cerebellum is coupled to nonmotor functions paralleling the evolutionary development of the large
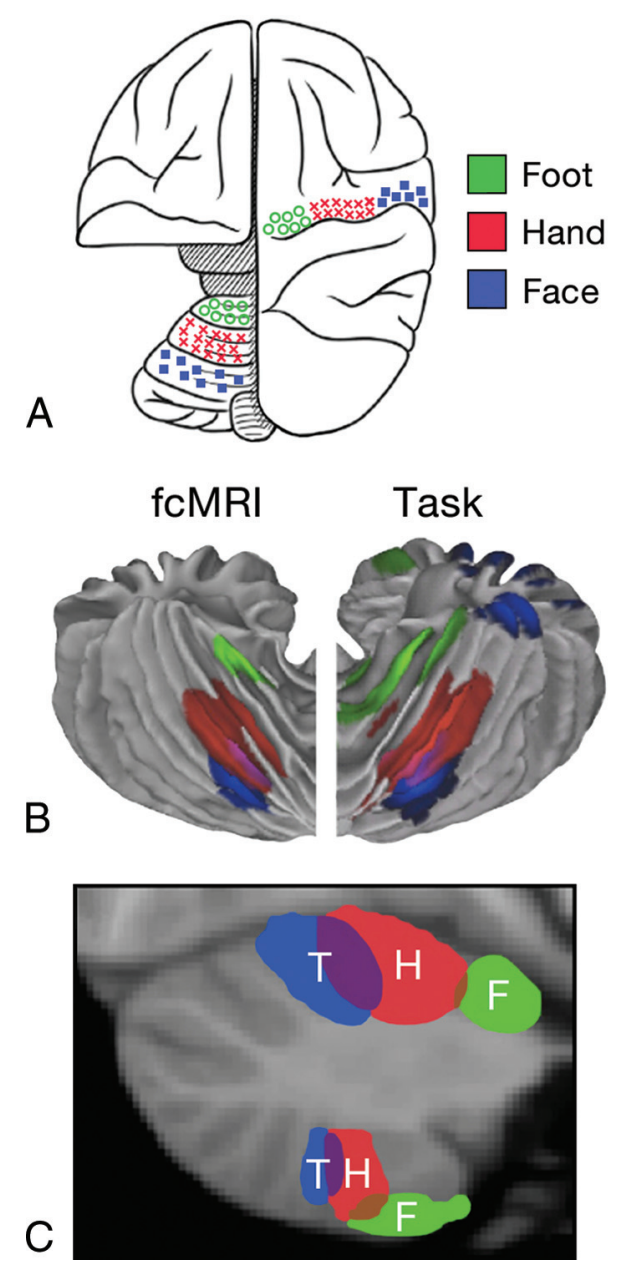

FIG 6. A, Schematic demonstration of the cerebral and cerebellar functional locations of the foot (green), hand (red), and face (blue) in the monkey. B, Cerebellar locations of the foot (green), hand (red), and tongue (blue) in humans measured by fMRI. "fcMRI" refers to results based on functional connectivity studies. "Task" refers to results from task-based fMRI studies. C, Cerebellar locations of foot (F, green), hand ( $H$, red), and tongue (T, blue) representations in humans from fcMRI studies displayed on a parasagittal image. Note the mirror image representation of the somatomotor functions with the primary or dominant location in the anterior lobe of the cerebellum. Adapted from Buckner RL. The cerebellum and cognitive function: 25 years of insight from anatomy and neuroimaging. Neuron 2013;80: 807-15 with permission of Elsevier. ${ }^{31}$

nonmotor portions of the cerebrum, prefrontal, and association cortices.

Perhaps the most challenging basic issue for neuroradiologists is accommodating to the novel and perhaps astonishing idea that the cerebellum has fundamental cognitive and emotional functions, let alone the equally astonishing proposal that most functions of the cerebellum may be cognitive rather than motor in nature. Considerable clinical evidence supports the concept of cerebellar pathology associated with cognitive and psychiatric illnesses. Schmahmann ${ }^{24,25}$ was the first to propose the idea of a "dysmetria of thought" due to cerebellar dysfunction. This concept refers to the significant role of the cerebellum in sensory, cognitive, and affective processing. The "cerebellar cognitive affective syndrome" proposed by Schmahmann ${ }^{26}$ has proved to be clinically significant in disease recognition and understanding. The litany of other psychiatric disorders now associated with cer- 


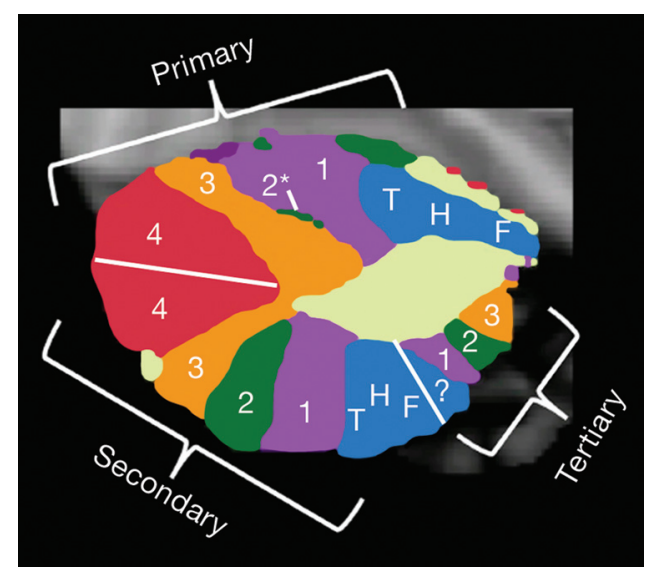

FIG 7. Topographic map of various cerebellar functions displayed on a parasagittal view of the left cerebellar hemisphere. The primary cerebellar distribution of cerebral functions is an orderly map of the somatomotor functions of the foot, hand, and tongue (blue) in the anterior lobe followed by a hierarchy of association cortices labeled 1-4 (magenta, green, orange, red) on the superior surface of the cerebellum. An inverted secondary representation in reverse order is seen on the inferior cerebellar surface. A small tertiary representative map is hypothesized to be present in the posterior lobe as well. Adapted from Buckner RL. The cerebellum and cognitive function: 25 years of insight from anatomy and neuroimaging. Neuron 2013;80: 807-15 with permission of Elsevier. ${ }^{31}$

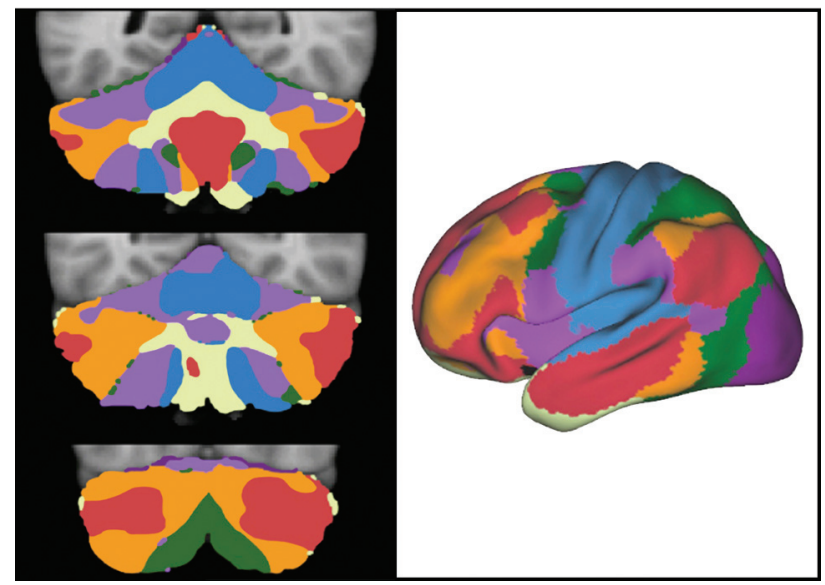

FIG 8. The 3 images on the left represent multiple coronal sections of the cerebellum with colors representing different cortical functions. The right-sided image is the cerebrum with the colors representing the different functional areas. The somatomotor cortex is blue. This cortex is represented at the more medial aspect of the cerebellum. Most of the human cerebellum, however, is linked to cerebral association networks, including executive networks (orange) and the default network (red). These association networks have multiple cerebellar representations. Adapted from Buckner RL. The cerebellum and cognitive function: 25 years of insight from anatomy and neuroimaging. Neuron 2013;80:807-15 with permission of Elsevier. ${ }^{31}$

ebellar pathology includes bipolar disorder, posttraumatic stress disorder, attention deficit autism spectrum disorders, and schizophrenia. ${ }^{12,27}$ Many physicians, however, remain skeptical about cognitive impairment due to cerebellar lesions. Part of this skepticism may be due to the lack of sensitivity of most traditional tests to evaluate cerebellar function because those tests were mostly designed to detect motor abnormalities. ${ }^{28}$ Another part may be a lack of awareness/understanding of the precise nature of the more nuanced functional abnormalities to look for on the clinical examination of cerebellar functions. Even so, not everyone is convinced of cerebellar cognitive functions, and some effectively express a healthy skepticism. ${ }^{29}$ For most neuroradiologists engaged in fMRI studies, however, the cerebellar activation observed during functional testing that was once dismissed as an aberration or an exercise in technical rationalization should now be viewed with a more critical eye.

The next Functional Vignette will review some of the important anatomic pathways that correlate with the cognitive functions of the cerebellum.

Disclosures: Vincent Mathews_UNRELATED: Grants/Grants Pending: GE Clinical Trial, ${ }^{*}$ National Institutes of Health, ${ }^{*}$ Comments: both pending; Payment for Lectures (including service on Speakers Bureaus): Eli Lilly, Comments: Amyvid Speakers Bureau in 2013. *Money paid to the institution.

\section{REFERENCES}

1. Nolte J. The Human Brain: An Introduction to its Functional Anatomy. 6th ed. Philadelphia: Mosby/Elsevier; 2009

2. Combettes M. Absence compléte du cervelet, des pédoncules postérieurs et de la protubérance cérébrale chez une jeune fille morte dans sa onziéme anneé. Bull Soc Anat Paris 1831;5:10

3. Holmes G. A form of familial degeneration of the cerebellum. Brain 1907;30:23

4. Babinski J. Expos des Travaux Scientifiques. Paris: Masson; 1913

5. Holmes G. The symptoms of acute cerebellar injuries due to gunshot injuries. Brain 1917;40:461-534

6. Holmes G. Clinical symptoms of cerebellar disease and their interpretation. Lancet 1922:2:59-65

7. Adrian ED. Afferent areas in the cerebellum connected with the limbs. Brain 1943;66:289-315 CrossRef

8. Dow RS. The evolution and anatomy of the cerebellum. Biol Rev Camb Philos Soc 1942;17:179-220 CrossRef

9. Passingham RE. Changes in the size and organisation of the brain in man and his ancestors. Brain Behav Evol 1975;11:73-90 CrossRef Medline

10. Passingham RE, Wise S. The Neurobiology of the Prefrontal Cortex. Anatomy, Evolution and the Origin of Insight. London: Oxford University Press; 2012

11. Purves D, Augustine GJ, Fitzpatrick D, et al. Neuroscience. 4th ed. Sunderland: Sinauer Associates; 2008

12. Fatemi SH, Aldinger KA, Ashwood P, et al. Consensus paper: pathological role of the cerebellum in autism. Cerebellum 2012;11:777807 CrossRef Medline

13. Leiner HC, Leiner AL, Dow RS. Cognitive and language functions of the human cerebellum. Trends Neurosci 1993;16:445-47 Medline

14. Matano S. Brief communication: proportions of the ventral half of the cerebellar dentate nucleus in humans and great apes. Am J Phys Anthropol 2001;114:163-65 Medline

15. Schneider GE. Brain Structure and Its Origins in Development and in Evolution of Behavior and the Mind. Cambridge: MIT Press; 2014

16. Timmann D, Drepper J, Frings M, et al. The human cerebellum contributes to motor, emotional and cognitive associative learning: a review. Cortex 2010;46:845-57 CrossRef Medline

17. Konczak J, Timmann D. The effect of damage to the cerebellum on sensorimotor and cognitive function in children and adolescents. Neurosci Biobehav Rev 2007;31:1101-13 CrossRef Medline

18. Murdoch BE. The cerebellum and language: historical perspective and review. Cortex 2010;46:858-68 CrossRef Medline

19. Wang D, Buckner RL, Liu H. Cerebellar asymmetry and its relation to cerebral asymmetry estimated by intrinsic functional connectivity. J Neurophysiol 2013;109:46-57 CrossRef Medline

20. Buckner RL, Krienen FM, Castellanos A, et al. The organization of the human cerebellum estimated by intrinsic functional connectivity. J Neurophysiol 2011;106:2322-45 CrossRef Medline 
21. Habas C, Kamdar N, Nguyen D, et al. Distinct cerebellar contributions to intrinsic connectivity networks. J Neurosci 2009;29:8586-94 CrossRef Medline

22. Krienen FM, Buckner RL. Segregated fronto-cerebellar circuits revealed by intrinsic functional connectivity. Cereb Cortex 2009;19: 2485-97 CrossRef Medline

23. O'Reilly JX, Beckmann CF, Tomassini V, et al. Distinct and overlapping functional zones in the cerebellum defined by resting state functional connectivity. Cereb Cortex 2010;20:953 CrossRef Medline

24. Schmahmann JD. An emerging concept: the cerebellar contribution to higher function. Arch Neurol 1991;48:1178-87 CrossRef Medline

25. Schmahmann JD. Dysmetria of thought: clinical consequences of cerebellar dysfunction on cognition and affect. Trends Cog Sci 1998; 2:362-71 CrossRef
26. Schmahmann JD. Disorders of the cerebellum: ataxia, dysmetria of thought, and the cerebellar cognitive affective syndrome. J Neuropsychiatry Clin Neurosci 2004;16:367-78 CrossRef Medline

27. Shakiba A. The role of the cerebellum in neurobiology of psychiatric disorders. Neurol Clin 2014;32:1105-15 CrossRef Medline

28. Noroozian M. The role of the cerebellum in cognition: beyond coordination in the central nervous system. Neurol Clin 2014;32:1081104 CrossRef Medline

29. Glickstein M. What does the cerebellum really do? Curr Biol 2007; 17:R824-27 CrossRef Medline

30. Haines DE. Fundamental Neuroscience for Basic and Clinical Applications. 4th ed. Philadelphia: Elsevier/Saunders; 2013

31. Buckner RL. The cerebellum and cognitive function: 25 years of insight from anatomy and neuroimaging. Neuron 2013;80:807-15 CrossRef Medline 